\title{
Use of Debate as a Pedagogical Tool in Psychiatry Residency Teaching: A Cross-Sectional Study
}

\author{
Qian Hui Chew' \\ Xian Ying Seet ${ }^{2}$ \\ Kang $\operatorname{Sim}$ (D) $^{3}$
}

'Research Division, Institute of Mental Health, Singapore; ${ }^{2}$ Department of Psychological Medicine, Tan Tock Seng Hospital, Singapore; ${ }^{3}$ West Region, Institute of Mental Health, Singapore
Correspondence: Kang Sim

West Region, Institute of Mental Health,

10 Buangkok View, 539747, Singapore

Tel +65 63892000

Fax +6563855900

Email kang_sim@imh.com.sg
Purpose: Despite the potential benefits of the use of debate as a teaching tool in promoting active self-directed and reflective learning, there are few studies examining its use within postgraduate training including psychiatry residency training. We aim to study this pedagogical tool and hypothesize that within psychiatry residency training, preference for the use of debates during teaching of a common topic is associated with better learning processes and outcomes such as better motivation, engagement of the learners, promotion of critical thinking and understanding of the subject content.

Subjects and Methods: All second-year psychiatry residents from 2015 to 2019 who underwent a specific teaching session on "Neurobiology of Psychosis" (which was conducted using debate) were administered a study questionnaire following the session. Between-group comparisons, correlational and path analyses were conducted to examine the relationship between use of debate and specific learning processes and outcome.

Results: Overall, 66 out of 80 (82.5\%) residents participated in the survey. The preferred use of debate was associated with better motivation, engagement, facilitation of critical thinking, understanding, equipping and better overall rating of the teaching session. Path analyses found that the relationship between preference for debate as a teaching tool and overall rating of the teaching was partially mediated by better engagement, felt relevance to the learning needs and better understanding.

Conclusion: The effectiveness of debate as perceived by psychiatry residents is consistent with self-determination and related learning theories and extant literature on its use as a pedagogical tool. This behoves the need to consider more of its use alone or in combination with other teaching methods in enhancing learning outcomes within psychiatry residency teaching and other training programmes.

Keywords: engagement, motivation, critical thinking, understanding

\section{Introduction}

Within residency training programs including psychiatry residency training, a large proportion of teaching of core curriculum topics tended to be conducted through lecture style format or didactics. ${ }^{1}$ A major concern about the direct provision of information via didactics pertains to whether it encourages deeper thought, and promotes understanding and clinical reasoning. ${ }^{2-4}$ In addition, during psychiatry residency training, learners will inevitably encounter complex issues related to diagnoses, treatment, and ethical dilemmas and these issues may be filled with uncertainty as there may not be standard answers to such clinical scenarios. Furthermore, clinical decisions often entail considerations of different sources of information available, garnering a holistic perspective and a critical appraisal of the 
clinical and external factors unique to each individual patient in a specific context which is dynamic and that can change over time. ${ }^{5}$ The adoption of debates as a pedagogical tool shows potential for this purpose of deeper learning in practice. ${ }^{6}$ Additionally, the use of debates could cater to different learning styles, ${ }^{7}$ which can better prepare residents to serve in an evolving healthcare landscape. ${ }^{8}$

What is unique about debate as a teaching tool? The process of debate requires the learner to consider different viewpoints raised, reflect, internalize them, and finally arrive at a reasoned judgement about a controversial issue. ${ }^{9}$ This can take place in both individual and group settings. ${ }^{9}$ Debate as a pedagogical tool potentially targets the key components of effective learning by actively engaging learners, encouraging in-depth exploration and consideration of problems, and inculcating skills to communicate their opinions in a clear and concise manner. ${ }^{10-12}$ Debate requires research, teamwork, preparation of logical arguments, critical listening and honing of communication and presentation skills, ${ }^{13}$ and studies have shown that learners find the debate format to be more engaging and interesting than the didactic style of teaching. ${ }^{14,15}$ Yet, to date, there have been few studies examining the use and effectiveness of debate as a pedagogical tool in postgraduate training including psychiatry residency training. Existing literature have only revealed several studies which were conducted at the undergraduate level and even fewer at the postgraduate level, ${ }^{5}$ namely, within emergency medicine, paediatric surgery and physical medicine and rehabilitation training programs. $^{15-17}$

Theories of adult learning relevant to debate as a pedagogical tool highlight three key components that predict positive learning outcomes, namely active involvement, intrinsic motivation, and reflection. ${ }^{18-21}$ First, adults are self-directed and expect to take responsibility for their learning. Hence, learning is enhanced when it is problemcentred, when learners are actively involved in the process, and are able to see the immediate value of the lesson being taught. ${ }^{18}$ Second, Ryan and Deci ${ }^{19}$ highlighted the importance of intrinsic motivation, which is enhanced by events that allow the learner to feel competent and autonomous which the process of debate preparation affords. Third, reflective learning allows one to consolidate their knowledge gained at work, ${ }^{20,21}$ and one way in which this is done is through the use of deliberate practice. ${ }^{22}$ Material learnt is repeatedly presented and discussed, allowing the learner to reflect upon it, as well as obtain feedback from others which occurs during debate. ${ }^{22}$ In addition, learning can be optimised according to social learning theory, ${ }^{23}$ which views learning as a social process and occurs when there is pursuit and active application of knowledge in a community setting which is germane to the context of debate preparation within a group.

\section{Aim and Hypothesis}

Based on the potential benefits of using debates in teaching and paucity of examination of its use in postgraduate training, we sought to examine the effectiveness of debate as a pedagogical tool in psychiatry residency training. We hypothesised that the use of debates will be associated with learning processes such as better motivation, engagement regarding the topic, understanding, equipping about the topic and better overall rating of the teaching session.

\section{Subjects and Methods Psychiatry Residency Training Program and Teaching Session}

In 2010, Singapore adopted a residency training system which is accredited by the Accreditation Council for Graduate Medical Education-International (ACGME-I) from USA and covers multiple medical and surgical specialties including psychiatry. Within the five-year National Psychiatry Residency Training, 4 out of the 5 years are accredited by ACGME-I and the final year by our local Joint Commission on Specialist Training within the Ministry of Health, Singapore. The five-year training curriculum consists of a wide range of didactic sessions as well as supervised clinical experience in general psychiatry and various sub-specialties including Child and Adolescent Psychiatry, Geriatric Psychiatry, Addictions Psychiatry, Community Psychiatry, Inpatient Psychiatry, Liaison Psychiatry, and Forensic Psychiatry. This crosssectional study recruited second-year psychiatry residents from intake years 2015 to 2019. The teaching session on "Neurobiology of Psychosis" is part of the scheduled didactics within "Psychotic Disorders Module" for Year 2 residents in the National Psychiatry Residency Training Program. The residents were informed of the debate topic one week before the teaching session and were given relevant papers to read and prepare individually and collectively. The motion for the debate was "Research in psychotic disorders has brought about better understanding and treatment of these conditions for our patients". The 
learners organised themselves to form two teams of four residents each. Each of the pre-selected speakers was given up to five minutes for their discourse and rebuttal of points raised by the members of the opposite team. The rest of the residents would participate as audience, and they could field their questions during the audience participation round. A debrief was conducted at the end of the debate session.

\section{Anonymised Questionnaire}

An anonymised questionnaire comprising of rated items was administered at the end of the teaching session to gather the perceptions of the residents regarding their learning experience and participation was voluntary. This study was conducted in accordance with the Declaration of Helsinki, although the need for informed consent was waived as no identifiers were collected as part of the study. This was in accordance with the guidelines given by the Institutional Review Board of the Institute of Mental Health and Domain Specific Review Board of the National Healthcare Group. The questionnaire was developed by the authors in consultation with other faculty staff from the residency program. Questions were asked about the relationship between the use of debates and learning processes of interest to faculty staff, such as enhancing motivation, engagement, promotion of critical thinking, understanding about the topic, equipping, and overall rating of the teaching session. The items in the questionnaire were rated along a 5-point Likert Scale ranging from 1 (Strongly Disagree) to 5 (Strongly Agree) for all except the last item which was rated along a 5-point Likert scale from poor (1-2 points) to average ( 3 points) and excellent (4-5 points). The study was approved by the Institutional Review Board of the Institute of Mental Health and Domain Specific Review Board of the National Healthcare Group (DSRB reference no. 2014/00422)

\section{Statistical Analyses}

All statistical analyses were conducted using SPSS 23.024 and SmartPLS v.3.2.7. ${ }^{25}$ The Jonckheere-Terpstra test ${ }^{26,27}$ and Spearman correlation analysis ${ }^{28}$ were used to examine the relationship between residents' preference for debates and other aspects of the teaching session. Path analysis was performed to examine the mediational learning processes between use of debate and overall outcome of the teaching session, respectively.

\section{Results}

\section{Group Differences Based on Preference for Use of Debate}

Sixty-six out of $80(82.5 \%)$ second-year residents responded to the survey. We grouped residents into three groups based on their level of preference for debates. The "low", "moderate", and "high" groups consisted of residents who rated 3 and below (Neutral/Disagree/Strongly Disagree), 4 (Agree), and 5 (Strongly Agree), respectively, for the question "The use of debate helped me in my appreciation of the subject covered in this session". The "low" group consisted of 8 residents $(12.1 \%)$, the "moderate" group of 36 residents (54.5\%), and the "high" group of 22 residents (33.3\%). A Jonckheere-Terpstra test for ordered alternatives was performed to compare the median scores for each group on other aspects of the teaching session. Significant differences were found between the groups for all aspects of learning such as better motivation, engagement, promotion of critical thinking, understanding, equipping about the topic and better overall rating of the teaching session (all $p<0.05$ ).

Post-hoc tests revealed differences between the "low" and "high" groups in that strong appreciation of use of debates was associated with better overall rating of the session $\left(J_{T}=150, p=0.001\right)$, better level of motivation following the session, better engagement in learning, and better understanding of the topic (all $p<0.05$ ). When comparing the "moderate" and "high" groups, stronger appreciation of use of debates was additionally associated with better ratings on promotion of critical thinking and equipping about the topic apart from better motivation, engagement and understanding (all $p<0.05$ ).

\section{Correlation Analysis}

Spearman correlation analysis revealed that the appreciation for the use of debates in the teaching session was correlated with better motivation $\left(r_{s}=0.408, p<0.01\right)$, engagement $(r s=0.394, \mathrm{p}<0.01)$, promotion of critical thinking ( $r s=0.25, \mathrm{p}<0.05)$, understanding of the subject $\left(r_{s}=0.375, p<0.01\right)$, equipping $(r s=0.445, \mathrm{p}<0.01)$, and overall rating of the teaching $\left(r_{s}=0.514, p<0.001\right)$.

\section{Path Analysis}

Path analyses were conducted to examine mediators in the relationship between appreciation for debate as a teaching tool and overall rating of the session. The factors as experienced and expressed by the residents in terms of better 
engagement of the subject matter, better understanding, and felt relevance to learning needs partially mediated the relationship between appreciation for debates and overall rating of the session ( $p<0.05$ for all paths) (see Figure 1).

\section{Discussion}

There were several main findings in this study. First, residents who strongly appreciated the use of debates for the teaching session reported motivation, engagement, better promotion of critical thinking, understanding, equipping and better overall rating of the session. Second, preference for the use of debates was positively correlated with various aforementioned learning aspects. Third, we found significant mediators (better engagement, understanding, felt relevance to learning needs) for the relationship between appreciation for use of debate and overall rating of the session.

As observed in the results from group comparisons and correlational analyses, greater appreciation of the use of debates was associated with better motivation and engagement to learn about the topic. Consistent with the selfdetermination theory, ${ }^{19}$ a sense of autonomy is instilled through the preparation for the debate session as residents are required to conduct extensive research in order to formulate convincing arguments. Studies investigating the use of debates as a pedagogical tool found significant improvements in the participants' research skills pre- and post-debate, ${ }^{13,29,30}$ thus increasing a sense of competence related to the topic. In the process of debate preparation and presentation, the learner is a self-directed learner and is actively engaged in the topic of interest. ${ }^{18}$ Of note, some studies have also found that learners perceived debates to be more engaging and interesting as a teaching method. ${ }^{10,14,15,17}$ In a study conducted among paediatric surgery residents, ${ }^{17}$ it was reported that $87 \%$ of the audience found it a new and enjoyable style of learning and 75\% wanted more of such sessions. This suggests that educators should seek ways to incorporate debates in residency training, particularly for topics that residents may find challenging or technical in order to boost motivation and engagement in learning.

Preference for the use of debate in learning was also associated with promotion of critical thinking, increased understanding, equipping and better overall rating of the session as observed in the correlational and path analyses. The discussion within the team prior to the debate, the process of debate and attendance to the points raised by the other team, consideration of rebuttal points and questions during audience participation allowed for constant feedback and reflective learning, ${ }^{20}$ which can promote critical thinking and increase understanding of the topic. $^{13,14,17,29,31-33}$ A better understanding of the topic

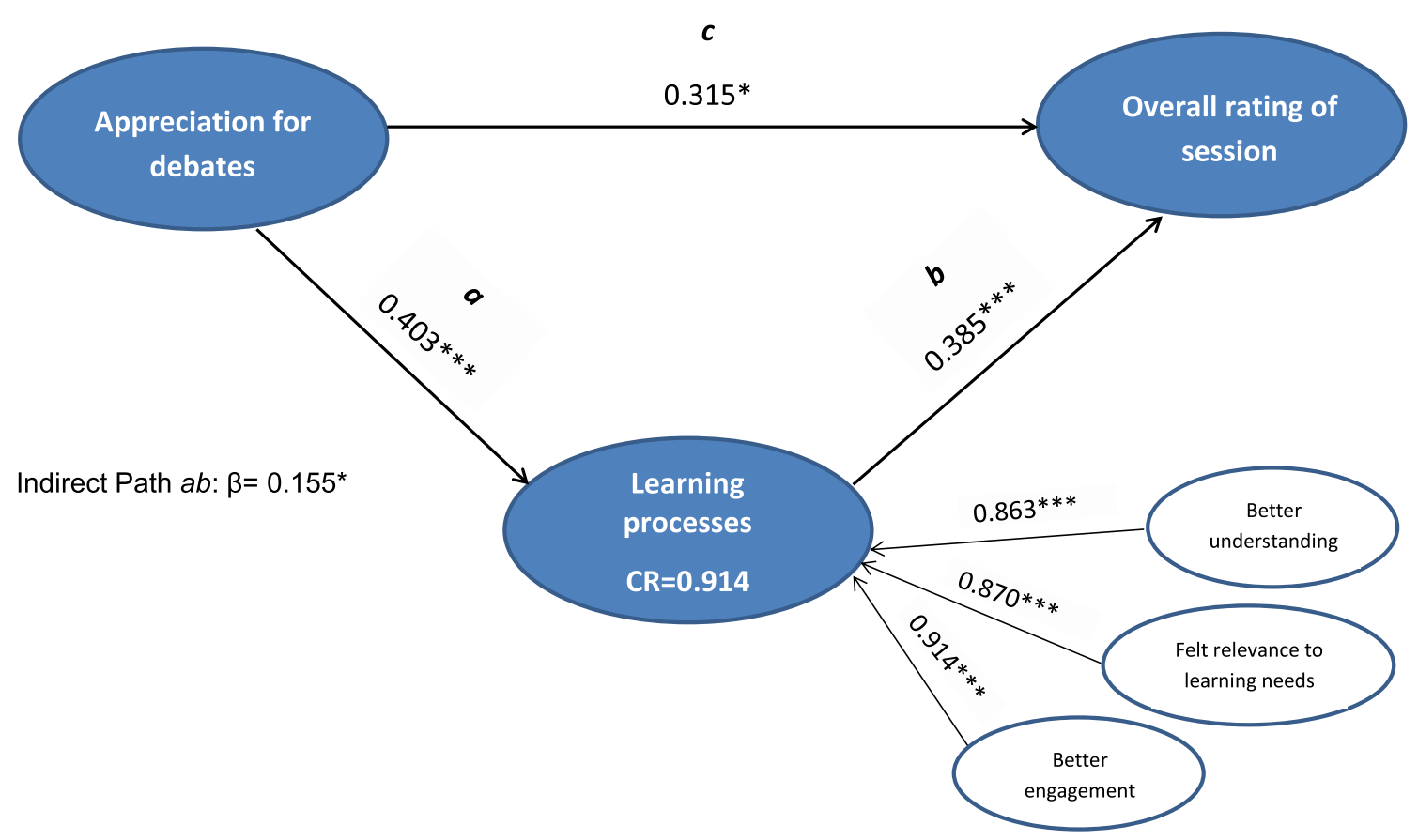

Figure I Appreciation for debates and overall session ratings partially mediated by learning aspects.

Notes: ${ }^{*} \mathrm{p}<0.05,{ }^{*} * * \mathrm{p}<0.001$.

Abbreviation: $C R$, composite reliability. 
in turn can further motivate and engage the learner to delve further into the area and examine the topic of interest from different perspectives through the repeated process of questioning and self-evaluation. ${ }^{13,15,29}$ In addition, consistent with the social theory of learning, small group discussions constitute "communities of practice",23 and represent social activities where learning and thinking also take place when debate is involved. Deliberate consideration of the pertinent debate points raised within a group can also result in better equipping as was observed in this study. $^{22}$ This suggests that the benefits reaped from using debates as a pedagogical tool are maximised when learners are encouraged to constantly reflect and evaluate various perspectives. Educators should therefore allocate sufficient time during debate sessions to allow for such in-depth learning to take place individually and collectively.

There are several challenges on the use of debates in teaching, some of which have been acknowledged in previous studies. For a debate session to be effective, a lot of prior preparation is required for the learner ${ }^{34,35}$ and classes should ideally be smaller to encourage adequate and effective participation. ${ }^{10}$ Insufficient preparation by the learner for the debate before the session can reduce the effectiveness of the session for learning. In addition, for debate to be an effective teaching method, discussions have to be well-facilitated by tutors who are comfortable with this form of training and learning. ${ }^{34}$ It is also important to recognise that the use of debates as a teaching method may not suit those learners who are uncomfortable with public speaking and arguing for and against a motion. Some students may contribute more within the session in terms of preparation and presentation which may be related to their interest level and acquired knowledge of the topic ${ }^{14}$ while others may participate less, ${ }^{31}$ hence the degree of learning may thus vary to some extent. Additionally, the use of debates may lead to perceived and oversimplified categorical responses to different topics as mere right/wrong or true/false, ${ }^{36,37}$ which may influence the process of learning. If the one is keen to defend a point and sway others simply to win the debate, the learner may lose the opportunity to weigh different factors and appreciate nuances regarding the topic. ${ }^{35,38}$

\section{Limitations of the Study}

First, even though feedback is anonymised, we need to consider the possibility that residents may still be affected by social desirability bias which may influence the accuracy of the responses. ${ }^{10}$ Second, the size of the sample is modest but it captures the responses of the same cohort year within the same teaching session over several years. Third, as this is a cross-sectional study, future longitudinal studies examining the effects of using debates over time on the understanding and further learning of the topic of interest would clarify the impact of the use of debates for sustained learning.

\section{Practical Suggestions}

In light of the results, debates can be considered as a teaching tool that can be combined with other pedagogies during residency training. First, the teaching faculty should review the content of different topics to determine whether the use of debate is appropriate. For example, controversies in psychiatry and ethical conundrums may lend themselves better to the use of debate as a way to engage the learner, encourage reflection and increase understanding of the issues involved. ${ }^{30,31}$ Second, there should be adequate time given for the debate preparation by the learners so that they can fully participate for maximum learning during the session. ${ }^{31}$ Third, pre- and postdebate quizzes can be administered to assess learner's understanding of the topic more objectively and help to evaluate the effectiveness of the use of debate. Fourth, faculty with domain knowledge should debrief residents at the end of each session to address the appropriate points raised during the debate so as to allow for a deeper understanding of the topic that was debated.

\section{Conclusion}

In conclusion, the use of debate in teaching within our psychiatry residents was associated with learning processes and better learning outcome which were consistent with extant learning theories related to self-directed learning, intrinsic motivation, reflective learning. Future studies should explore its use in combination with other teaching methods, as well as evaluate its effectiveness in such contexts in order to enhance learning outcomes within psychiatry residency teaching and other training programmes.

\section{Abbreviation}

ACGME-I, Accreditation Council for Graduate Medical Education-International.

\section{Acknowledgments}

This research received no specific grant from any funding agency in the public, commercial, or not-for-profit sectors. 


\section{Disclosure}

The authors report no conflicts of interest in this work.

\section{References}

1. Sawatsky AP, Zickmund SL, Berlacher K, Lesky D, Granieri R. Understanding resident learning preferences within an internal medicine noon conference lecture series: a Qualitative Study. J Grad Med Educ. 2014;6(1):32-38. doi:10.4300/JGME-06-01-37.1

2. Miller CJ, McNear J, Metz MJ. A comparison of traditional and engaging lecture methods in a large, professional-level course. $A d v$ Physiol Educ. 2013;37(4):347-355. doi:10.1152/advan.00050.2013

3. Prince M. Does active learning work? A review of the research. $J$ Eng Educ. 2004;93(3):223-231. doi:10.1002/j.2168-9830.2004. tb00809.x

4. Crouch $\mathrm{CH}$, Mazur E. Peer instruction: ten years of experience and results. Am J Phys. 2001;69(9):970-977. doi:10.1119/1.1374249

5. Ang RX, Chew QH, Sum MY, Sengupta S, Sim K. Systematic review of the use of debates in health professions education - does it work? GMS J Med Educ. 2019;36:Doc37.

6. Garrett M, Schoener L, Hood L. Debate: a teaching strategy to improve verbal communication and critical-thinking skills. Nurse Educ. 1996;21(4):37-40. doi:10.1097/00006223-199607000-00015

7. Dantas LA, Cunha A. An integrative debate on learning styles and the learning process. Soc Sci Humanit Open. 2020;2(1):100017. doi:10.1016/j.ssaho.2020.100017

8. Taylor DCM, Hamdy H. Adult learning theories: implications for learning and teaching in medical education: AMEE guide no. 83. Med Teach. 2013;35(11):e1561-e1572. doi:10.3109/ 0142159X.2013.828153

9. Freeley A, Steinberg D. Argumentation and Debate: Critical Thinking for Reasoned Decision Making. 11th ed. Belmont, CA: Wadsworth; 2005.

10. Randolph DS. Student perceptions of the use of debate as a teaching strategy in the allied health professions. J Allied Health. 2007;36: e13-e29.

11. Osborne A. Debate and student development in the history classroom. New Dir Teach Learn. 2005;103(103):39-50. doi: $10.1002 / \mathrm{tl} .202$

12. Firmin MW, Vaughan A, Dye A. Using debate to maximize learning potential: a Case Study. J Coll Teach Learn. 2007;4(1):19-32.

13. Darby M. Debate: a teaching-learning strategy for developing competence in communication and critical thinking. J Dent Hyg. 2007;81:78.

14. Khan SA, Omar H, Babar MG, Toh CG. Utilization of debate as an educational tool to learn health economics for dental students in Malaysia. J Dent Educ. 2012;76:1675-1683.

15. Mamtani M, Scott KR, Deroos FJ, Conlon LW. Assessing EM patient safety and quality improvement milestones using a novel debate format. West J Emerg Med. 2015;16(6):943-946. doi:10.5811/ westjem.2015.9.27269

16. Nguyen VQ, Hirsch MA. Use of a policy debate to teach residents about health care reform. J Grad Med Educ. 2011;3(3):376-378. doi:10.4300/JGME-03-03-32

17. Ong CC, Narasimhan KL. A novel learning experience: case-based, evidence-based debate. Med Educ. 2010;44(5):515-516. doi:10.1111/ j.1365-2923.2010.03644.x
18. Knowles M, Holton EI, Swanson R. The Adult Learner: The Definitive Classic in Adult Education and Human Resource Development. Burlington, MA: Elsevier; 2005.

19. Ryan RM, Deci EL. Self-determination theory and facilitation of intrinsic motivation, social development and well being. $\mathrm{Am}$ Psychol. 2000;55(1):68-78. doi:10.1037/0003-066X.55.1.68

20. Schon DA. The Reflective Practitioner: How Professionals Think in Action. London: Temple Smith; 1983.

21. Schon DA. Educating the Reflective Practitioner. San Francisco, CA: Jossey-Bass; 1995.

22. Duvivier RJ, Van Dalen J, Muijtjens AM, Moulaert VRMP, Van Der Vleuten CPM, Scherpbier AJJA. The role of deliberate practice in the acquisition of clinical skills. BMC Med Educ. 2011;11(1):101. doi:10.1186/1472-6920-11-101

23. Wenger E. Communities of Practice: Learning, Meaning, and Identity. New York: Cambridge University Press; 1998.

24. IBM. SPSS statistics for windows [computer software]. Version 23.0. Armonk, NY: IBM Corp; 2015.

25. Ringle CM, Wende S, Becker J-M. SmartPLS3. Boenningstedt: SmartPLS GmbH; 2015. Available from: http://www.smartpls.com. Accessed May 27, 2021.

26. Jonckheere AR. A distribution-free k-sample test against ordered alternatives. Biometrika. 1954;41(1-2):133-145. doi:10.1093/biomet/41.1-2.133

27. Terpstra TJ. The asymptotic normality and consistency of Kendall's test against trend, when ties are present in one ranking. Indag Math. 1952;14:327-333. doi:10.1016/S1385-7258(52)50043-X

28. Spearman C. The proof and measurement of association between two things. Am J Psychol. 1904;15(1):72-101. doi:10.2307/1412159

29. Lampkin SJ, Collins C, Danison R, Lewis M. Active learning through a debate series in a first-year pharmacy self-care course. Am J Pharm Educ. 2015;79(2):25. doi:10.5688/ajpe79225

30. Hanna LA, Barry J, Donnelly R, et al. Using debate to teach pharmacy students about ethical issues. Am J Pharm Educ. 2014;78(3):57. doi:10.5688/ajpe78357

31. Lin SJ, Crawford SY. An online debate series for first-year pharmacy students. Am J Pharm Educ. 2007;71(1):12. doi:10.5688/aj710112

32. Rubin RW, Weyant RJ, Trovato CA. Utilizing debates as an instructional tool for dental students. J Dent Educ. 2008;72(3):282-287. doi:10.1002/j.0022-0337.2008.72.3.tb04494.x

33. Shaw JA. Using small group debates to actively engage students in an introductory microbiology course. J Microbiol Biol Educ. 2012;13 (2):155-160. doi:10.1128/jmbe.v13i2.420

34. Tyler I. Strengths, Weaknesses and Applicability of Teaching Methods. University of Toronto, Nevis Consulting Group; 2009.

35. Lieberman SA, Trumble JM, Smith ER. The impact of structured student debates on critical thinking and informatics skills of Second-year medical students. Acad Med. 2000;75(Supplement): S84-S86. doi:10.1097/00001888-200010001-00027

36. DeYoung S. Teaching Strategies. Redwood City, CA: AddisonWesley; 1990.

37. Combs HW, Borne G. The impact of marketing debates on oral communication skills. Bull Assoc Bus Commun. 1989;52(2):21-25. doi:10.1177/108056998905200209

38. Griswold LS. Debate as a teaching strategy. Am J Occup Ther. 1999;54(4):427-428. doi:10.5014/ajot.54.4.427 


\section{Publish your work in this journal}

Advances in Medical Education and Practice is an international, peerreviewed, open access journal that aims to present and publish research on Medical Education covering medical, dental, nursing and allied health care professional education. The journal covers undergraduate education, postgraduate training and continuing medical education including emerging trends and innovative models linking education, research, and health care services. The manuscript management system is completely online and includes a very quick and fair peer-review system. Visit http://www.dovepress.com/testimonials.php to read real quotes from published authors.

Submit your manuscript here: http://www.dovepress.com/advances-in-medical-education-and-practice-journal 